\title{
A DOCUMENT MANAGEMENT SYSTEM FOR THE CONSERVATION OF CULTURAL HERITAGE BUILDINGS
}

\section{Paulo B. Lourenço}

University of Minho, Department of Civil Engineering, ISISE

Campus Azurem, 4800-058 Guimarães, Portugal

Tel: +351 (253) 510200

Fax: +351 (253) 510217

Email: pbl@civil.uminho.pt

\section{Fernando Peña (contact author)}

Instituto de Ingeniería, Universidad Nacional Autónoma de México

Edificio 2 - 401, Circuito Escolar, Ciudad Universitaria, 04510 Mexico city, Mexico Tel. +52 (55) 56233600 ext. 8404

E-mail: fpem@pumas.iingen.unam.mx

\section{Miguel Amado}

University of Minho, Department of Civil Engineering

Campus Azurem, 4800-058 Guimarães, Portugal

Tel: +351 (253) 510200

Fax: +351 (253) 510217

Email: migamado@civil.uminho.pt

\begin{abstract}
A Document Management System (DcMS) for the efficient organization and visualization of the data related to conservation projects in cultural heritage buildings applied to a case study is presented. The objective of the system is to allow for the interchange of information between different specialists, to prevent the loss of data through time and to promote technical awareness of general public. For this purpose, a database for the management of the information involved in the works carried out in the Monastery of Santa Maria de Salzedas (Portugal) was created. The newly developed system collects the information about the Monastery produced in a period of five years by different specialists (architects, engineers, geologists, physicists and material scientists). The system is fully web based and includes a Back-End for easy uploading of information and a Front-End for automatic visualization and downloading of the information. Both Back- and Front-End are accessible via an Internet connection.
\end{abstract}

Keywords: Information Management System, Recording, Documentation, Multimedia, Conservation, Internet 


\section{INTRODUCTION}

Conservation and interventions of cultural heritage buildings require an interdisciplinary approach with specialists of different areas of knowledge, for example: non-destructive tests, advanced structural analyses, urban planning, traditional materials (masonry, lime, wood, etc.), mechanisms of deterioration, traditional and innovative techniques of intervention, compatibility, philosophy and ethics of the conservation, etc. However, the mere addition of different experts does not create a truly interdisciplinary team.

Anyone involved in the conservation of cultural heritage buildings is aware of the enormous amount of information generated by the different specialists, which is generally not handled adequately by owners and/or authorities involved in the process. The consequence is that valuable information is lost in a complex process of reaching a decision that involves many different experts. Information also tends to get forgotten or misplaced in the course of time. Sometimes it is even easier to find historical information than information regarding recent events.

In this context, the correct recording, documentation, management, dissemination and safe storage of the information generated during the intervention works have become a real challenge for the different specialists involved in an intervention project. It is noted that the purpose of documentation is to conserve an accurate record of historic properties, interventions, changes and everything that can be used in preservation and research of the architectural heritage (HABS, 1990).

Recording and documentation are also important because they: promote the economic value of the cultural heritage, such as cultural tourism and regional development; increase and strengthen the cultural and social identity at different levels (local, regional, international); contribute to prevent theft and illicit traffic of cultural heritage goods (GII, 1998).

However, recording and documentation are not enough. It is necessary to adopt inventories and databases for the correct management of the information, as well as, to make publicly available and to share the data contents. Only this combination allow for correct management and dissemination of the information, which results in identification, interpretation and preservation of the cultural heritage (GII, 1998). 
University of Minho (UMinho), in partnership with the Centre of Computer Graphics (CCG) and the Portuguese Institute of Architectural Heritage (formerly IPPAR, and presently IGESPAR) developed a Document Management System (DcMS) for the efficient administration and visualization of the data related to interventions of cultural heritage buildings. The development was based on a case study with extensive damage, which recently suffered major works in a cloister, namely the Monastery of Santa Maria de Salzedas (Portugal). A database was created for the management of all the information generated during the intervention process of 2005 and of all the information gathered or produced recently, selected by different field of knowledge. The information is accessible via internet (http://www.civil.uminho.pt/salzedas) for practitioners and on the monastery for visitors, in way that a non-specialist and a team specialist can obtain information with different contents.

The aim of this paper is to establish the theoretical frame of reference in which the system is based on and to explain the main characteristics of the DcMS. For this purpose, this paper is divided in three parts. In the first one, the principles proposed by the International Council of Monuments and Sites (ICOMOS) for the management of information of monuments are addressed, and the advantages of using the internet in the management of information are discussed. The second part of the paper describes briefly the Monastery of Santa Maria de Salzedas and its rehabilitation process. Finally, the last part describes the characteristics and objectives of the developed system.

\section{CULTURAL HERITAGE INFORMATION SYSTEMS (CHIS)}

It has been recognized that good conservation decisions are based on correct information. However, it has also identified that, often, there is no communication between "suppliers" (e.g. photographers, heritage recorders, photogrammetrists, surveyors) and "users" (e.g. researchers, conservation specialists, project managers, planners) of documentation (LeBlanc, 2005). This means that records might be prepared with purposes much different from the ones required by users.

For example, often historical information of a given building is not available or is very limited, due to the loss of records or because existing records were prepared 
with purposes much different from the ones to which they are used today. Therefore, "extrapolation" of the information is needed, making the process of understanding the past almost as complex as the problem of foreseeing the future. Here, extrapolation means the process of obtaining information about materials, typology, techniques of construction, geometry, dimensions or other relevant issues from the previous experience in constructions of similar period and architectural style (Peña and García-Córdova, 2004).

As a consequence of the above, correct recording, documentation, management and dissemination of the information has become a much relevant task for different organizations around the world (EH, 2007; GII, 1998; LeBlanc, 2005; HABS, 1990; ICOMOS, 1996; RecordDIM, 2007). In this context, an important assignment has been the development of principles, standards, guidelines, vocabularies and other tools for recording, documenting, management and dissemination of the information related to cultural heritage.

In this last topic, the recognition of the benefits of creating Cultural Heritage Information Systems (CHIS) has been growing in the last years (ArsVirtual, 2007; Cannataci et al., 2003; Henze et al., 2005; Romão, 2006; Zonta et al., 2008). These systems allow the common access to documentation created and managed by different organisations. The term CHIS includes a wide variety of systems with different purposes. As for example: a) Expert System (ES) for monitoring a structure in real time; b) Geographic Information System (GIS) with the scope to manage, display and use efficiently all forms of geographically referenced information; c) Inventory System (InS), which main purpose is an Information System (IS) developed for documentation; d) Tourist Information System (TIS) which is an IS developed towards tourist scope; e) Content Management System (CMS) is an InS which create automatically Web contents from a separately structure (layout); and f) Document Management System (DcMS) is an IS with a central data storage included in a web-based central document and a structured index.

The CHIS developed here can be considered as a combination of InS, TIS, CMS and DcMS. This last term is possibly the best definition of the system presented here. According to Henze et al. (2005), a DcMS can be defined as an Internet-based Information System which have central data storage (database), common data 
structures, data backup and editing components. Moreover, the system must have an indexed structure combined with possibilities to classify information, taking into account the properties the documents stored in the database. All these components are internet based and additional software on the user's end should be not required, except for an Internet browser. Generally, the DcMS is developed with free and open source software in view of a potential redistribution of the system code to other similar projects.

\section{THEORETICAL FRAMEWORK OF THE DCMS}

The DcMS described here was developed following the recommendations proposed by the International Council of Monuments and Sites (ICOMOS), which can be found on its charter Principles for the recording of monuments, groups of building and sites (ICOMOS, 1996). The Venice Charter and the ISCARSAH recommendations, both documents also proposed by $\operatorname{ICOMOS}(1964,2003)$, were considered also, as they address the conservation and maintenance of cultural heritage buildings.

In order to establish the theoretical framework in which the DcMS was based, a brief review on the ICOMOS recommendations for recording architectural heritage is made next. The main objective of these ICOMOS recommendations is to adopt an adequate methodology for the intervention, so that the value of a cultural heritage building can be maintained. One important issue is that information generated remains available along the time. In fact, information is capital in each intervention because it is the basis for understanding the evolution of the building and allows interchange of experience between the different specialists involved, being a leading thread in the methodology to find the correct path for an intervention.

The Venice Charter on its $16^{\text {th }}$ article considers the necessity to have records of each stage of the intervention works (cleaning, consolidation, rearrangement, etc). Moreover the publication, preservation and the availability of the information are recommended (ICOMOS, 1964).

Following this proposal, ISCARSAH recommendations (ICOMOS, 2003) stress the need of recording information in order to make easier the decisions to be taken and the safety assessment of the structure. In this way, the historical information, the 
present state and all acquired information, diagnosis, safety evaluation, interventions must be recorded and documented in an Explanatory Report. The Explanatory Report should contain (ICOMOS, 1996): a) the type, form, dimensions and characteristics from outside and inside of the cultural heritage building; b) the intrinsic value of the monument (historic, cultural, artistic, scientific, etc), as well as the significance of the materials, elements, decorations, inscriptions, machinery, gardens, landscapes, etc.; c) the technology and skills used during its construction and any relevant intervention; d) history of the origins of the building including the date of construction, authorship, ownership, original design, decoration, use, etc.; e) subsequent history of the building as different uses, historical events, alteration to the structure and architectural style; f) the history of management and interventions (maintenance and repairs); and g) an assessment of the current condition of the building, including the conflicts and risks from human or natural causes (environmental pollution, actual use, etc).

Due to the large amount of information required for the Explanatory Report it is not always possible to have or to publish only one document. Therefore, the correct management of the different documents becomes compulsory. In this context, the Principles charter (ICOMOS, 1996) gives some recommendations to deal adequately with the information; which consider:

Level of recording and sharing. Depending to whom the information is addressed, the level of recording and sharing should be different, namely if the objective is public information, technical information, administrative and politic information, or planning and research information. These levels try to close the gap between "suppliers" and "users" in order that the information has the "purpose" required for the users. Updated information should also be available to the statutory authorities, to concerned professionals and to the public (if applicable), in order to be used for research on the heritage, management, maintenance and disaster prevention, development controls and other administrative and legal processes.

Responsibility for conservation and maintenance of architectural heritage, as well as the recording process, should be shared among the owner, specialists, government and users. Here, responsibility includes asking for the explanatory 
report, the safe storage and long-term preservation of the information, the availability of access, etc.

Planning. Recording information requires a good and precise planning that must include the examination and adequacy of the existing sources of information. The plan should include the level and objective of recording, the way of sharing, storing and disseminating the information, the preservation along time, among other aspects.

Contents. Every record should have complete identification. It is noted that all the compiled information should include the sources from where it is obtained. Likewise, depending on the reasons for recording, different levels of detailing will be required. Thus, a standardised format and index of the records should be used in order to facilitate the exchange and retrieval of information. The location of the records should be made public.

Stability. The materials and techniques used for recording and compiling the completed information must guarantee their stability along the time. Moreover, for correct management, dissemination and sharing records the place where the original records will be stored must assure durability of the information without decay according to recognized international standards. In this way a full back-up copy should be stored in a separate safe location.

It is noted that the ICOMOS Principles (1996) are open for new technologies such as multimedia and internet technologies, and they do not fix a specific format or media. This is important, because the advance of technology allows the incorporation of new media for appropriate handling of information, e.g. (Romão et al., 2006).

\section{INTERNET AND MULTIMEDIA TECHNOLOGIES AS A TOOL FOR INFORMATION MANAGEMENT}

Internet is an excellent tool that fulfils the requirements for the correct management, dissemination and sharing of records, namely: a) the original electronic version can be safely archived; b) backups are easily made and can be stored in a different and safe place; c) updated records can be easily incorporate; d) the format of the records can be standardized and indexed; e) information is accessible 24 hours a day, year round, from any point of the world; f) information can be published, disseminated and be easily accessible and/or restricted depending on the 
classification of the information and the user; and g) information can be easily presented in different languages in real time allowing its dissemination around the world.

However, this technology also brings some new problems regarding the longterm preservation of electronic documents. For example: the maintenance of the server where the system is running, the technology used for creating, editing or viewing some files might become obsolete, the life-time of the hardware, etc. A detailed discussion of this problem is outside the scope of the present study but a solution of these problems consist in the continuous maintenance of the system. In other words, the abandonment, negligence and forgetfulness of any documental archive are the main causes of its loss.

On the other hand, the most common multimedia tools used in web-based systems can be grouped in the following: $360^{\circ}$ panoramic views, interactive tours by means of hotspots ("access points or links"), 3D models, images, videos and drawings, databases, or some combination of the previous ones.

There are basically two ways to show information, either simple visits, which present the site solely with an additional window with information, or complex visits, in which menus and windows incorporate complementary information. An interactive three-dimensional model allows the exploration of the space freely, with points of interest (paintings, constructive elements, etc.) appearing as hotspots with additional information. But, the combination of $360^{\circ}$ panoramic views with interactive tours has the advantage of being easier to handle, faster and with higher quality of image, than the $3 \mathrm{D}$ models. In general, a 3D form of navigation is not recommended for frequent users, due to the limited interactivity that the models allow and due to the long time required in the navigation. As an alternative, some systems adopt a navigation processes that allows to access to the information in a more efficient way. The "3D model" has no longer a central role in the application, being placed to the same level as other forms to present information as, namely $360^{\circ}$ panoramic views, videos, photographs, drawings, graphs, texts, etc. This type of navigation allows to show much diversified information. 


\section{MONASTERY OF SANTA MARIA DE SALZEDAS}

The Cistercian Monastery of Santa Maria de Salzedas in Portugal was founded in the $12^{\text {th }}$ century. The building compound that arrived to our days (Fig. 1a) is the result of the intensive work campaigns in the $16^{\text {th }}$ and $18^{\text {th }}$ centuries, when two new cloisters were built, the interior space of the church was remodelled and the façade was completely rebuilt (Fig. 1b).

After the extinction of the religious orders in Portugal, in 1834, the monastery was dilapidated and several parts disappeared. After this process, only minor interventions were made. In 2005 the main cloister was subjected to a major intervention due to the imminent risk of collapse; see Lourenço et al. (2001) for details on the diagnosis and further details. As a part of the intervention project in 2005, it was decided to create a database to collect the information related to the intervention, as a case study demonstration of the modern possibilities of information management.

\subsection{Description of the actual monastery}

As other cases of Cistercian monasteries in Portugal, Salzedas' monastic compound occupied, at a certain moment, a central place of the urban space and it was the engine of growth and development of the town. The church, the western side (inn) and the fence worked as the frontier between public and private areas, as well as delimitated the urban nucleus that grew and developed to the north and west. The eastern and southern areas of the monastery are surrounded by a large agricultural area that still conserves the look and the limits defined by the antique fence of the monastery (Fig. 1a).

The Monastery and Church have a composed irregular plant, with horizontal disposition of masses that are representative of a typical plant of a Cistercian Abbey. It is the second greatest Cistercian monastery of Portugal, with in-plan dimensions of $75.0 \times 101.0 \mathrm{~m}^{2}$. The church, with the main façade oriented towards west, has also appreciable dimensions of $24.4 \times 37.0 \mathrm{~m}^{2}$ and a height of $19.0 \mathrm{~m}$, with a transept of $34.0 \times 10.2 \mathrm{~m}^{2}$ and one unfinished (south) tower of $6.8 \times 4.2 \mathrm{~m}^{2}$, with the height of the pediment in the main façade. Possibly, a second unfinished (north) tower would have been built under normal circumstances. 
The inn, the refectory, the dormitories, the cells, the storerooms, the barn and the garden disappeared. The Monastery has currently two cloisters. The main cloister substituted part of the two primitive cloisters. This main cloister is a classic model with its imposing pillars in the lower open gallery and the upper closed gallery (Fig. 1c). There is a second small cloister located west of the main cloister, with a small door for communication between the two. As the monastery was dilapidated for many years, very few elements remain now of this small cloister.

\subsection{Recording information during the rehabilitation of the main cloister}

The Portuguese Institute of Architectural Heritage (IPPAR) requested University of Minho to carry out the inspection and diagnosis of the main cloister, which was partly supported on temporary shoring, and to design subsequent remedial measures.

The state of degradation of the main cloister, evidenced by the damages widely distributed along the construction, recommend an urgent and global intervention in the monastery. As first step, exhaustive information about history, past interventions, materials, techniques of construction and historical damages was collected. From this information, it was possible to conclude that the damage affecting the stability of the construction in 2000 was not recent. There was evidence that in 1963 the western side of the main cloister was near to collapse. Major cracks in the vaults were described in 1980, as well as in 1981, and the vault of $2^{\text {nd }}$ floor of the southern side presented generalized cracking and separation between the walls and the infill material of the vaults (Lourenço et al., 2000, 2001).

Historical information was searched too. It was collected from archives of government institutions, libraries and on site survey. This information allowed to make an hypothetical reconstruction of the medieval monastery by means of a threedimensional computer model (Amado et al., 2006). This model is used in the application to represent part of the history of the monastery (Fig. 2).

All the works carried out (survey, modelling, rehabilitation, cleaning, etc) were recorded by means of photographs, drawings, videos and technical reports. It is worth to note that records include original condition of the monastery, development of works and final state (Fig. 3). 


\section{OBJECTIVES AND STRUCTURE OF THE DcMS}

A great amount of information was generated during the intervention works of the Main Cloister of the Santa Maria de Salzedas Monastery. The interchange of information among the different specialist (architects, engineers, geologists, physicists and material scientists) was a constant during the project and it allowed the correct development of the works. Therefore, at the end of the works emerged the necessity to preserve and handle correctly the information in order to avoid its loss after the conclusion of the project. In other words, the documentation of the works (including historical documentation) was fulfilled satisfactorily but it lacked to fulfil the preservation and sharing the information.

In addition, as the Monastery was dilapidated by many years, it was the interest of the authorities to recover the historic, cultural and artistic value of the second greatest Cistercian Monastery of Portugal. In this way, it was considered to provide to the visitors of the Monastery information about the intervention project in order to allow a better understanding of the monument and to show the conservation works carried out.

As consequence of these two facts, an innovative multimedia solution to increase the fruition of monuments and at the same time to manage technical information was created. This Document Management System (DcMS) was created by a multidisciplinary team that at the same time was a "supplier" and "user" of the documentation. This "vision" allowed to close the common gap between them.

From this point of view, the DcMS was planned considering the follow objectives and characteristics, see Figure 4 where its flux diagram is depicted:

Type of users. The system must be useful for both technical and tourist proposes. Therefore, the presentation and contents should be different depending on the user.

Technical information. The nature of the information presented in the DcMS is mainly technical, even for the general public. Therefore all the information collected during the intervention project should be available in the system.

Tourist information about the Monastery should be presented using virtual representation (VR), i.e. through multimedia tools. In order to promote the public awareness of technical aspects related to the conservation of monuments and 
historical constructions, information about the rehabilitation project should be presented.

Documental repository. The first objective of the DcMS was the creation of a "repository" for future interventions. Thus the first step was the design and development of a database for the correct management of all the information collected in the rehabilitation works. This task included an advanced system for search and browse the information contained in the database. For this propose, a standard form for the files uploaded to the database was adopted in order to facilitate the search (see subsection Back-End).

Access via Internet connection. The user interfaces should be implemented in order to be accessed through an Internet connection. This will allow to have information accessible 24 hours a day, year round, from any point of the world.

Maintenance of the system should be easy. Here, maintenance is understood as to have DcMS updated along the time, including change on contents (text, images, links, menus, etc.). Another requirement was that the maintenance could be done for personal which could be not involved in the original project and with only basic knowledge of internet and no knowledge on computer programming.

ICOMOS recommendations. The characteristics of the DcMS were proposed in order to fulfil the ICOMOS (1996) recommendations addressed above.

Type of navigation. The navigation to access the information was thought to be "redundant". This means that the access to the same information should be possible from different parts of the application or following different paths.

Consequently, the DcMS was structured based on three main characteristics, which define the way in which the information can be accessed, namely "spatial units", "level of access" and "thematic areas".

\subsection{Spatial Units}

The spatial units should be understood as the different areas in which the Monastery has been divided. There are six spatial units considered in the database (Fig. 5), namely the "Church", "Main Cloister", "Little Cloister", "Sacristy", "Inn" and "Chapter Room". 
These units can be divided in elements and sub-elements, associated with the information gathered. In this way, one navigation form is generated with a clear path to consult the respective contents.

\subsection{Level of Access}

Four different levels of access or users were defined and each one has different privileges of access to the system (Fig. 4), namely "Basic user", "Registered user", "Administrator" and "Superadministrator".

The Basic user level is intended for non-technical users or tourist visitors, in which the information about the monastery is presented by VR. The information presented at this level is limited to "tourist interest" and it is presented exploiting the main characteristics of multimedia tools (videos, $360^{\circ}$ panoramic views, 3D models, etc).

The Registered user is for technical users or technical visitors that required specific information about survey, inspection, diagnosis or execution projects. Searching information into the database is allowed and download of unrestricted files is possible. A username and password, which can be obtained automatically by free online registration, is necessary for access. Registration is required in order to have a record of the persons that access the database. The use of multimedia tools is limited and information without any post-processing is preferred at this level, such as reports in pdf or word files, Autocad ${ }^{\circledR}$ drawings, photographs, data sheets, testing bulletins, etc., in order to facilitate the navigation of frequently users.

Administrator and Superadministrator users are the only one that can access the Back-End (see next section). The Administrator user is for the partners involved in the project, with the possibility to add information to the database, update the application and unrestricted access to the database. Registration at this level is not automatic and must be carried out by the Superadministrator.

The Superadministrator is the webmaster of the application (site). This user can modify the structure of the webpage, create or delete thematic areas and modify the rights of the users. 


\subsection{Thematic Areas}

Thematic areas are the options for searching the information contained in the database. The database can be browsed through menus or hotspots in photographs, $360^{\circ}$ panoramic views or 3D model, see Figure 6. The thematic areas depend on the level of access (Visitor or Technical level). A tree-like structure was thought for the thematic areas (menus and submenus), in which each one can be subdivided in three different levels.

There are three main areas for visitor information (basic users), namely "History", "Present condition" and "Conservation". The main areas for registered users (technical information) are "Inspection and Diagnosis", "Survey", "Conservation", "Monitoring", "Recommendations" and "Database". However, it is worth to note that the thematic areas can be modified, deleted and added by the Superadministrator at any moment.

\section{DESCRIPTION OF THE DcMS}

The DcMS has two graphic interfaces: one public named Front-End and one restricted to the partners of the project called Back-End. This last interface is where the Administrator of the system can insert the information gathered via database. Thus, the Back-End should be intended as the user interface from which the contents of the Webpage (Front-End) are created and the way to manage the database. The Back-End will create automatically the Front-End or the public WebPages. Both interfaces can be accessed remotely via Internet connection.

The Back-End was created keeping in mind the requirements of future and continue maintenance (see previous section) in which personal not involved in the original project and with only basic knowledge of internet can become the Superadministrator of the DcMS. Therefore, high qualify personal in programming knowledge of the CCG have create the Backoffice of the System with these requirements. The so-called Backoffice includes the "source code" and the computational platform used (Fig. 7). 


\subsection{Backoffice}

Only a brief description of the technical implementation of the DcMS is made, since it is out of the scope of this paper. The system was designed in order to have dynamic web-pages, allowing to change the contents in the Front-End according with the requirements of the administrators of the system. Therefore, a server-side scripting technology was used, because this technology provides interactive web sites that interface to databases and to the ability to highly customize the response based on the user's requirements, access rights, or queries into databases (Wikipedia, 2008).

In this context, the platform used is the named LAMP platform which is a solution stack of software. This platform is compossed by the operating system Linux, Apache HTTP server, MySQL as the database management system and the programming langue PHP. This means that the DcMS was completely programmed by using a PHP scripting language, in combination with a MySQL database management system, which are essential components for running content management systems. Both PHP and MySQL are free and open source software.

\subsection{Back-End}

The structure of the Back-End was created with the aim of keeping it as simple as possible, so that it can be accessed and used by a non-specialist user, which can be an administrator or superadministrator, carrying out tasks related to the update, maintenance and continuity of the application. It is noted that login is required to access. Figure 8 depicts the flux diagram of the Back-End, which is detailed next.

The Back-End was divided in seven modules: Database; Home Page; Partners; Type of Users; Users; Elements; and Menus. Each module allows the later use of the Front-End, safety, maintenance and updating. Also, modules can be divided in two groups: function modules (Partners, Type of Users, and Users) and information modules (Database, Home Page, Elements, and Menus).

The function modules are related with the safety and correct operation of the application and the Superadministrator is the only one to have rights to access them. In the Module Users it is possible to change the rights of the single users (Registered, Administrator, Superadministrator), as well as, to recover password and personal information. Module Type of Users allows changing the types of "Level of Access" 
(types of users), creating or deleting new types of users. Only authorized Institutions (e.g. University of Minho, IPPAR, CCG) can propose persons to have rights of Administrator or Superadministrator users. Therefore, the authorized Institutions are registered in the Module Partners.

The contents presented in the Front-End are created with the Information modules, which can be created by Administrators. The information presented in the Home Page is created with the Module Home Page and is independent of the rest of the application. Module Data Base is the centre core of the application, here all files are uploaded and stored according to a specific form (Fig. 9).

In the file form, all the information about the file is recorded and will be used in the search options in the Front-End. The necessary information to upload a file is (see also Fig. 9): File name and location of the file in the computer connected to the internet and from which the application will make the upload; Title of the file as the application will record it in the database; Legend, which is a small text to describe the content of the file; Date of creation of file; Author of file, which can be a person or an institution; Format of file (jpg, mov, doc, pdf, dwg, etc.); Type of file (picture, document, report, drawing, movie, etc); Location in the building or spatial unit; Subject or thematic area; Association to element, which indicates that if the option is checked the file will be able to be part of a content in the Front End; Preview of the file allowing the user to preview the contents, which must be a picture in jpg or tiff format; Type of Element which the file will be associated to, only if the option Association to element has been checked before; Partner or institution owner of the file; Level of access for the file, e.g. if it is able for basic, registered or administrator users.

Modules Elements and Menus are used to create the contents shown in the FrontEnd. In these modules, information for both basic and registered users is created. Each Menu or thematic area has three different type of elements related (see also below): Image are files stored in the database as pictures, movies, panoramic views, 3D models, etc.; Text is just normal text; and Linked Image are image files with hotspots linked to specific information or files.

Figure 10 shows an example for the creation of contents. As it can see, the creation of contents is very easy. First, it is necessary to create an element entering in 
the Module Elements. Here, the Name of the element (a) and its Level of Access (b) are given. Clicking in the File Associated (c) a pop-window is displayed showing the files stored in the database. It is noted that only files stored in the database can be associated to an element. After this, it is necessary to enter in the Module Menus where the association of an element to a menu is carried out (d). Here a list of elements is displayed.

\subsection{Front-End}

Figure 11 shows two views of the Front-End of the DcMS, in which it is possible to see the different options and possibilities of the system. Figure 11a shows the Home Page of the application, in which information about the project is presented, as well as the partners of the project. Here there are links to enter the system as a basic user (bottom) or a registered user (top).

Figure $11 \mathrm{~b}$ shows a typical view of the Front-End of the application for registered users. It is noted that the Front-End for basic users is similar. The only difference is the contents (thematic areas and quality of information) and the absence of a search bar, since basic users do not have rights to access the database. The different elements in application are: menus and submenus; a linked image or image with hotspots; and a main window, in which the information is displayed.

The navigation to access the information was thought to be "redundant", thus it can be carried out through thematic areas (menus and submenus) and spatial units (linked images). This "redundant" type of navigation allows to access the same information from different parts of the application. The main menus or thematic areas are shown in a fixed top bar, while the submenus are displayed at the top-left of the screen. The bottom-left area displays the image with hotspots. The hotspots link with some particular information or display files stored in the database. The information is displayed in the main window. The information is presented as image elements (pictures, drawings, movies, panoramic views, 3D models, etc.) in the top, with text elements in the bottom.

Finally, there is a search bar to find any particular file stored in the database. Figure 12 shows a typical view of the navigation window of the database. This window shows the same fields as the file form associated with each file in the 
database. The download option will be turn on only if the user has at least the same rights as the file has (level of access).

\section{FINAL REMARKS}

It is known that an enormous volume of information is generated by different specialists during a conservation project in a cultural heritage building. This large amount of information is often not dealt correctly by the different specialists and responsible of the building. Therefore, it is common to lose valuable information through time.

In the last years, different organizations have addressed the need to collect and maintain information of a historical building in a modern conservation process of intervention, aiming at maintaining the value of the cultural heritage buildings. Information is the basis for understanding the evolution of a building, and is of much relevance to define the path for a correct intervention. Therefore, a set of principles and guidelines for a correct treatment of the information are available.

The Document Management System (DcMS) developed for the management of information produced during a case study (Monastery of Santa Maria de Salzedas in Portugal) follows the ICOMOS principles and recommendations, which can be used for other case studies.

The system is based on the creation of a database that makes possible the efficient management of all information related to past, present and future interventions of the Monastery, in a way that it would be easily accessible by anyone. In the same way, the use of a multimedia platform accessible via Internet allows to share and access the information by users with different levels of interest (a generic user or a practitioner). The structure of the DcMS allows an easy update of the application with the information that can be generated in the future by a user interface called Back-End. The Front-End representing the graphics user interface is materialized by automatically generated web pages.

\section{ACKNOWLEDGEMENT}

The Document Management System presented here is part of the project POCTI-HEC-60431-2004, Integrated approach for conservation and valuation of 
monuments, funded by FCT (Portuguese Science and Technology Foundation). F. Peña acknowledges funding from the FCT grant contract SFRH/BPD/17449/2004. The system was programmed by Engineers Ana Lima and Daniel Oliveira of the Centre of Computer Graphics (CCG).

\section{REFERENCES}

Amado, M., Lourenço, P.B., and Peña, F. 2006. Modelo tridimensional do Mosteiro de Santa Maria de Salzedas na Idade Média. Report 06 - DEC / E - 15. University of Minho.

ArsVirtual 2007. Internet site of ArsVirtual Espacio para la difusión del Patrimonio Cultural: http://www.arsvirtual.com/

Cannataci, J.A., Rivenc, R. Zammit, N.P., Borg, C., Guidi, G., and Beraldin, G.A., 2003. E-Heritage: The future for integrated applications in cultural heritage. CIPA 2003 XIX International Symposium. Antaly, Turkey.

EH 2007. Conservation principles. Policies and guidance for sustainable management of the historic environment. Draft document. English Heritage, London.

GII 1998. Documenting the cultural heritage. R Thornes and J Bold editors. Getty Information Institute, UK.

HABS 1990. Secretary of the Interior's standard and guidelines for architectural and engineering documentation: HABS/HAER Standards. Historic American Building Survey. US Department of Interior, Washington.

Henze, F., Lehmann, H., and Fischer-Genz, B. 2005. Development of an Internet-Based Information System for archaeological research and studies on urban history in Baalbek/Lebanon. CIPA 2005 XX International Symposium. Torino, Italy.

ICOMOS 1964. International charter for the conservation and restoration of monuments and sites (The Venice charter). International Council of Monuments and Sites. Available at: http://www.international.icomos.org/charters/charters.pdf

ICOMOS 1996. Principles for the recording of monuments, groups of building and sites. International Council of Monuments and Sites. Available at: http://www.international.icomos.org/charters/charters.pdf

ICOMOS 2003. ICOMOS Charter - Principles for the analysis, conservation and structural restoration of architectural heritage. International Council of 
Monuments and Sites. Available at: http://www.international.icomos.org/charters/charters.pdf

LeBlanc, F. 2005. RecorDIM Task Group 1 - Principles \& guidelines for recording, documentation and information management of the built cultural heritage. CIPA 2005 XX International Symposium. Torino, Italy.

Lourenço, P.B., Vasconcelos, G., Barreiros Martins, J., Ramos, L., and Jalali, S. 2000. Diagnóstico sobre as condições de estabilidade do claustro do Séc. XVII do Mosteiro de Salzedas, em Tarouca. Process LEC 31/2000. Universidade do Minho.

Lourenço, P.B., Vasconcelos, G., and Ramos, L. 2001. Assessment of the stability conditions of a Cistercian cloister. In: Studies in Ancient Structures, eds. G. Arun and N. Seçkin. Istambul, Turkey: Yldiz Technical University, pp. 669 - 678.

Peña, F., and García-Córdova, R. 2004. Relación de la Ingeniería con la Historia en el proceso de restauración de los edificios históricos. XIV Congreso Nacional de Ingeniería Estructural, paper 55. Acapulco, Mexico.

RecordDIM 2007. International heritage documentation standards. Draft Report of Task Group 16. Recording, Documentation and Information Management (RecordDIM).

Romão, X., Paupério, E., Guedes, J., and Costa, A. 2006. Authoring and multimedia technologies for management and presentation of information on heritage constructions. In: Structural Analysis of Historical Construction, vol. 2, eds. P. Lourenço, P. Roca, C. Modena and S. Agrawal. New Delhi, India: 175-182.

Wikipedia (2008). Internet site of Wikipedia, the free encyclopedia: http://en.wikipedia.org/wiki/Main_Page

Zonta, D., Pozzi, M., and Zanon, P. 2008. Managing the historical heritage using distributed technologies. International Journal of Architectural Heritage, 2: 200-225. 
a)
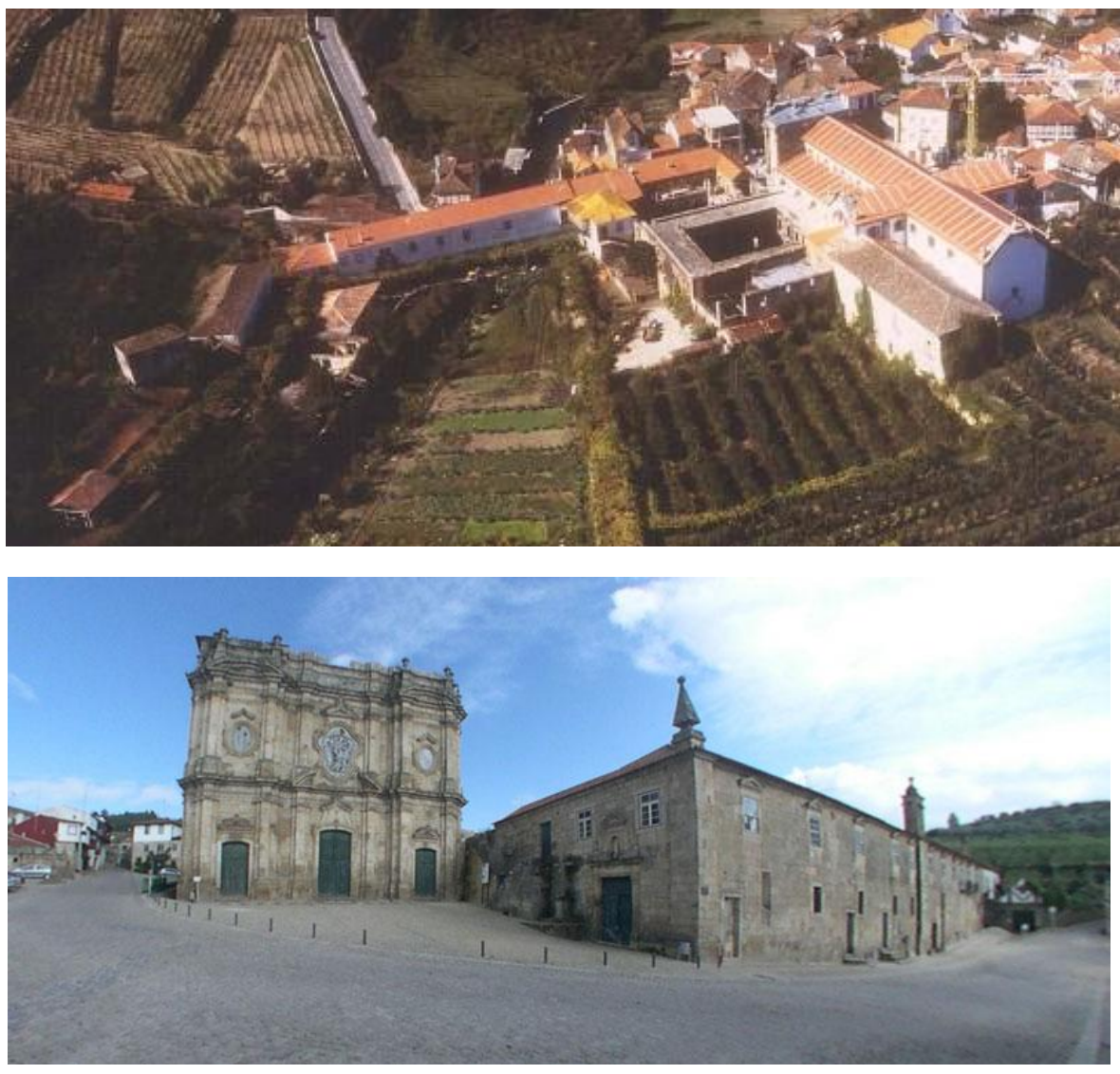

b)

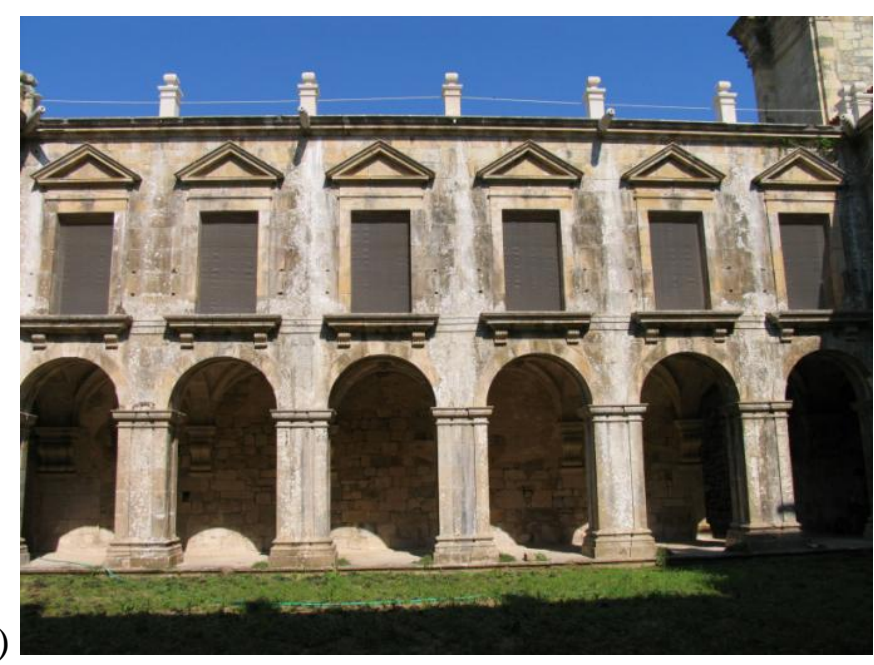

Figure 1. The Cistercian Monastery of Santa Maria de Salzedas: a) Aerial view from south-eastern side; b) Church façade and main entrance of the actual monastery; c) Façade of the main cloister. 
a)
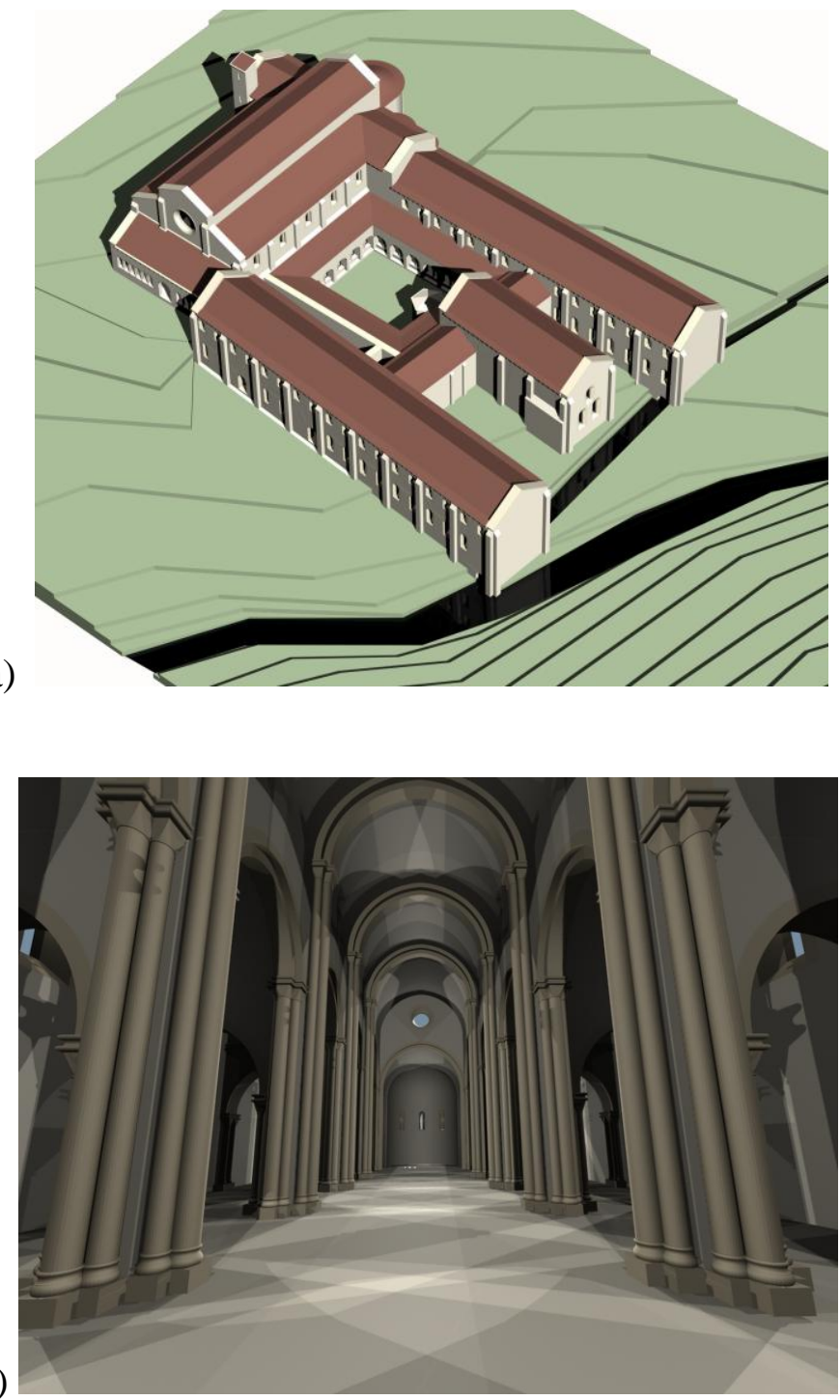

Figure 2. Hypothetical three-dimensional model of the medieval monastery: a) General view; b) view of the main nave of the church. 
a)

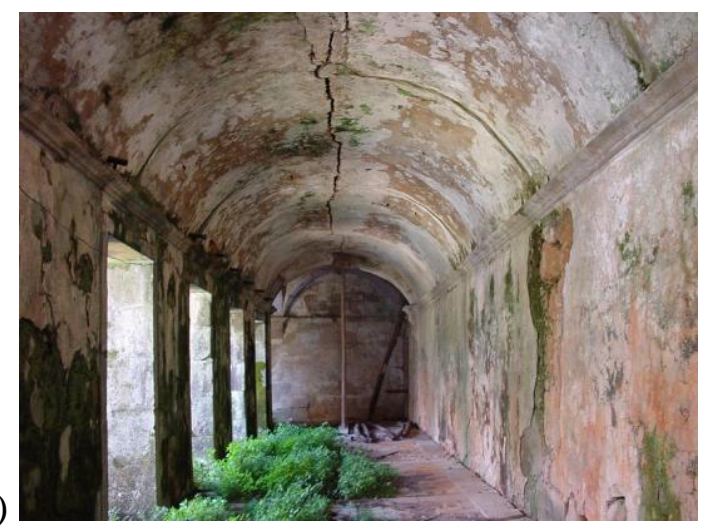

b)

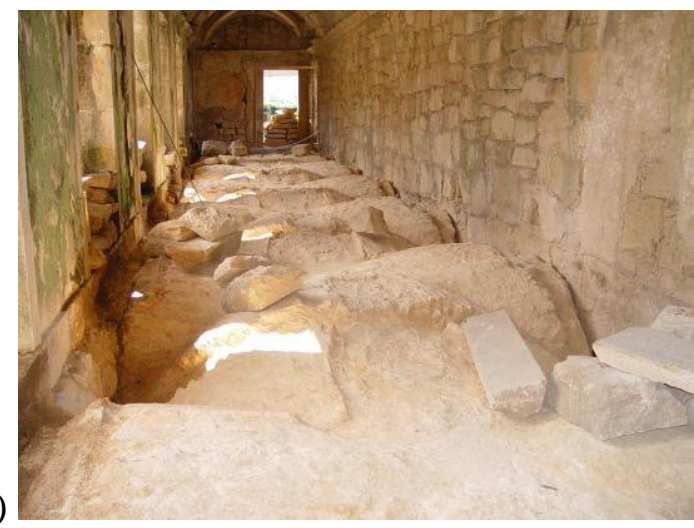

c)

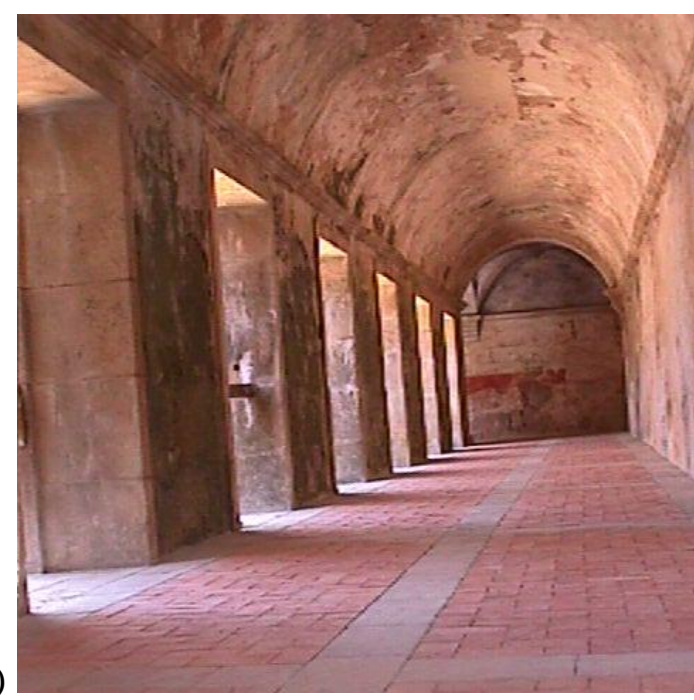

Figure 3. Example of recorded photographs for the intervention in the first floor of the main cloister: a) Original condition; b) During rehabilitation works; c) Final state. 


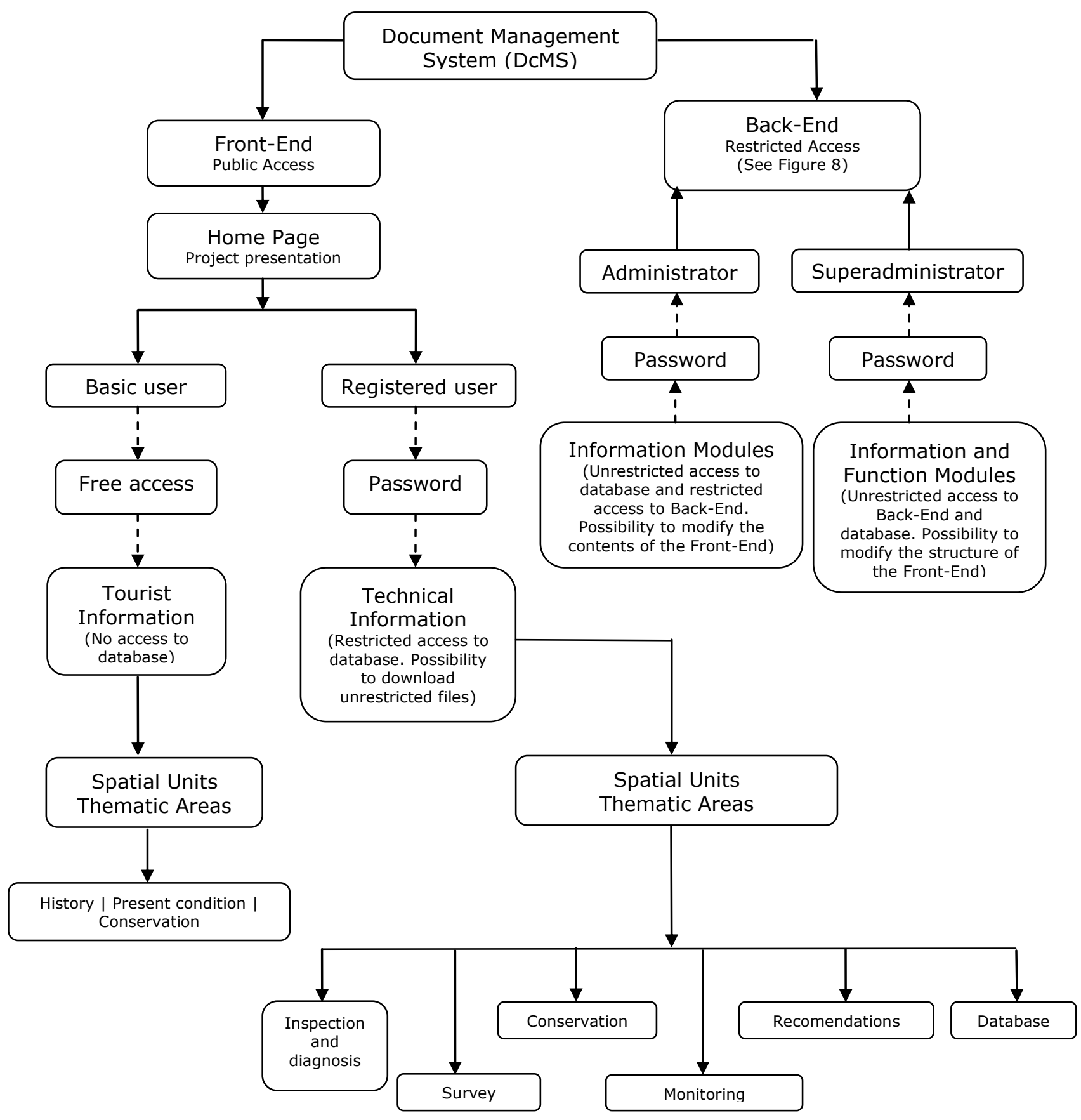

Figure 4. General flux diagram of the DcMS. 


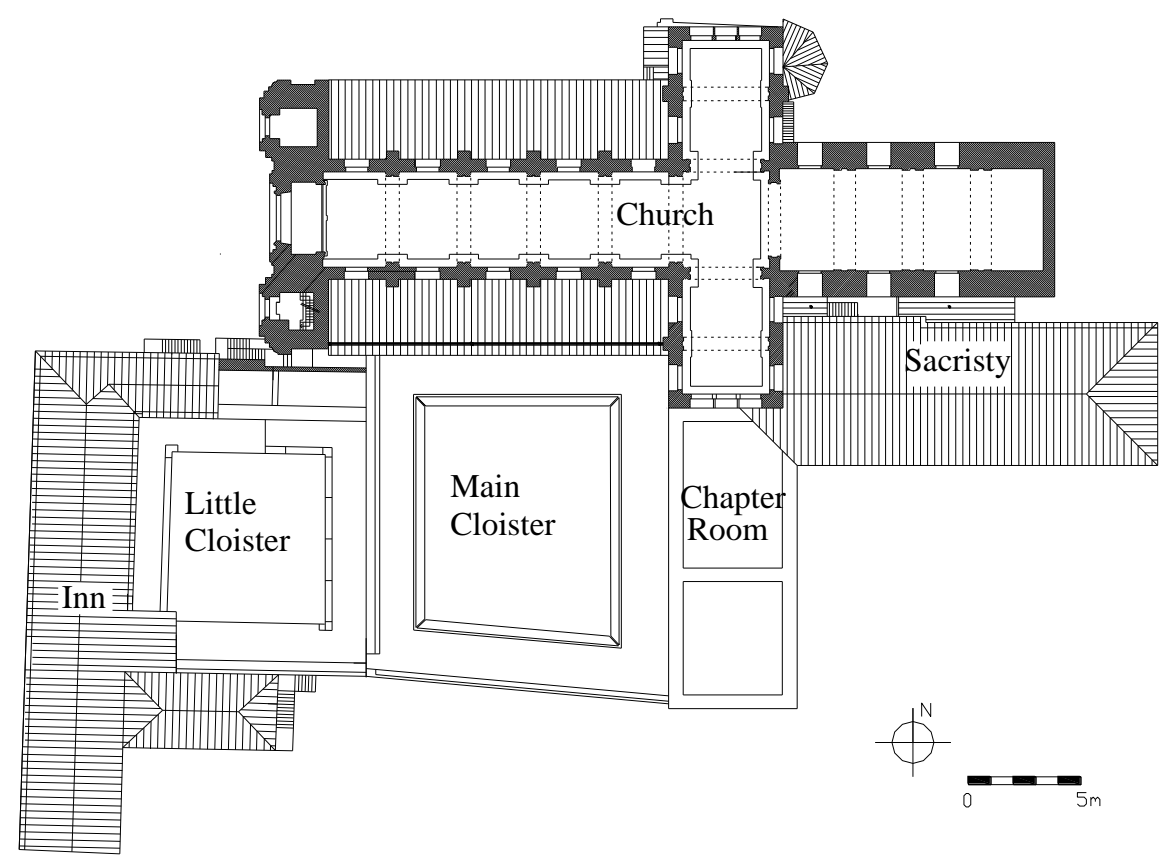

Figure 5. Spatial units of the Monastery of Santa Maria de Salzedas. 


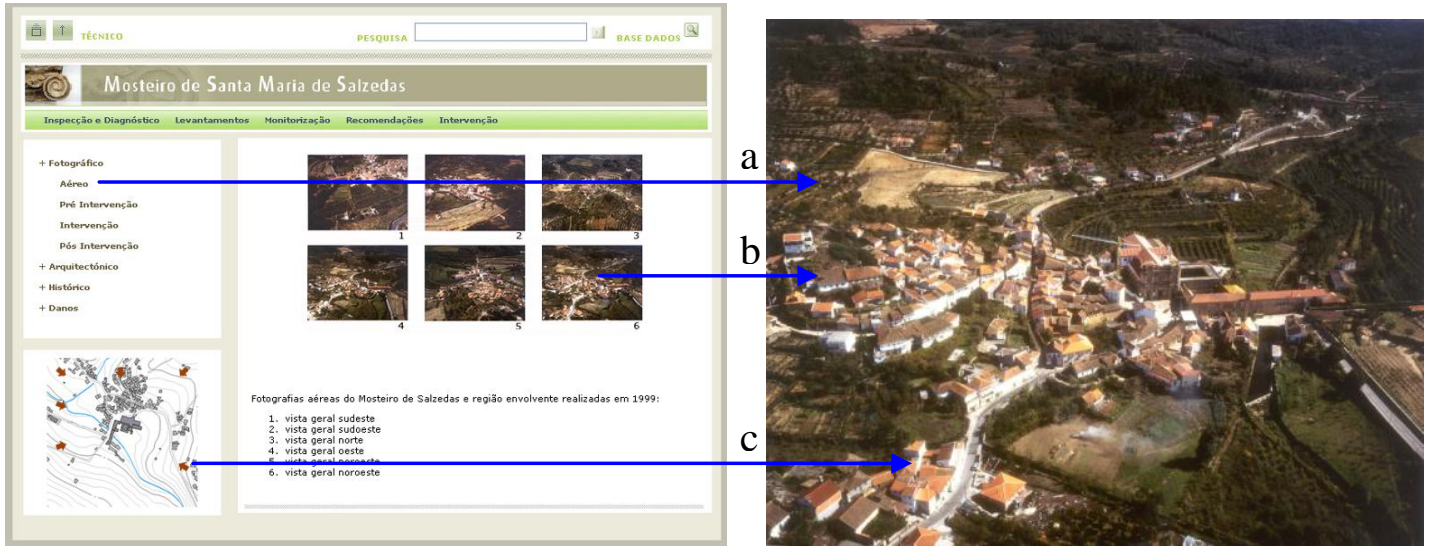

Figure 6. The database can be browsed through: a) menus, b) photographs, 3D models, panoramic views, and c) hotspots. 


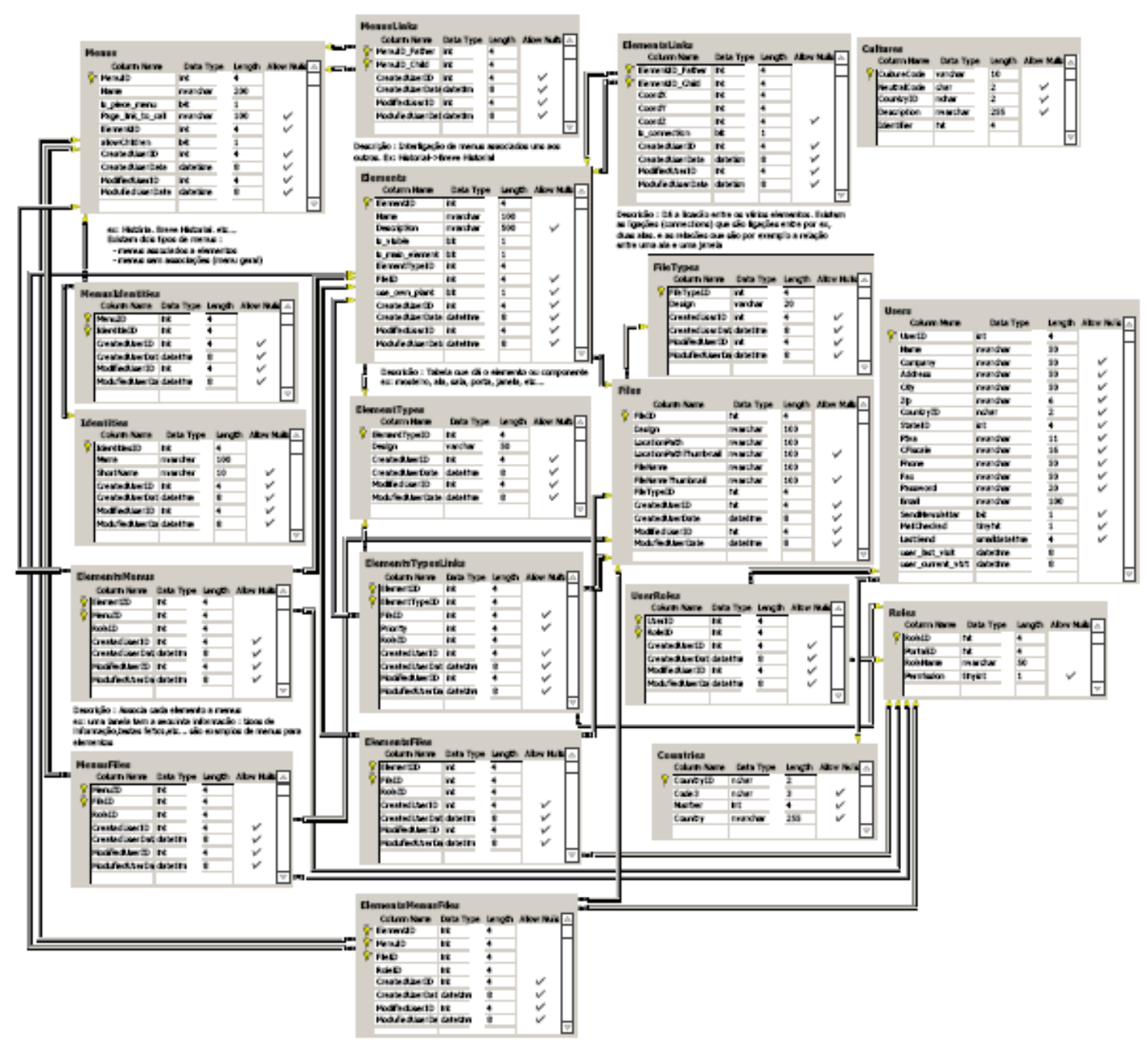

Figure 7. Scheme of the Backoffice implementation. 


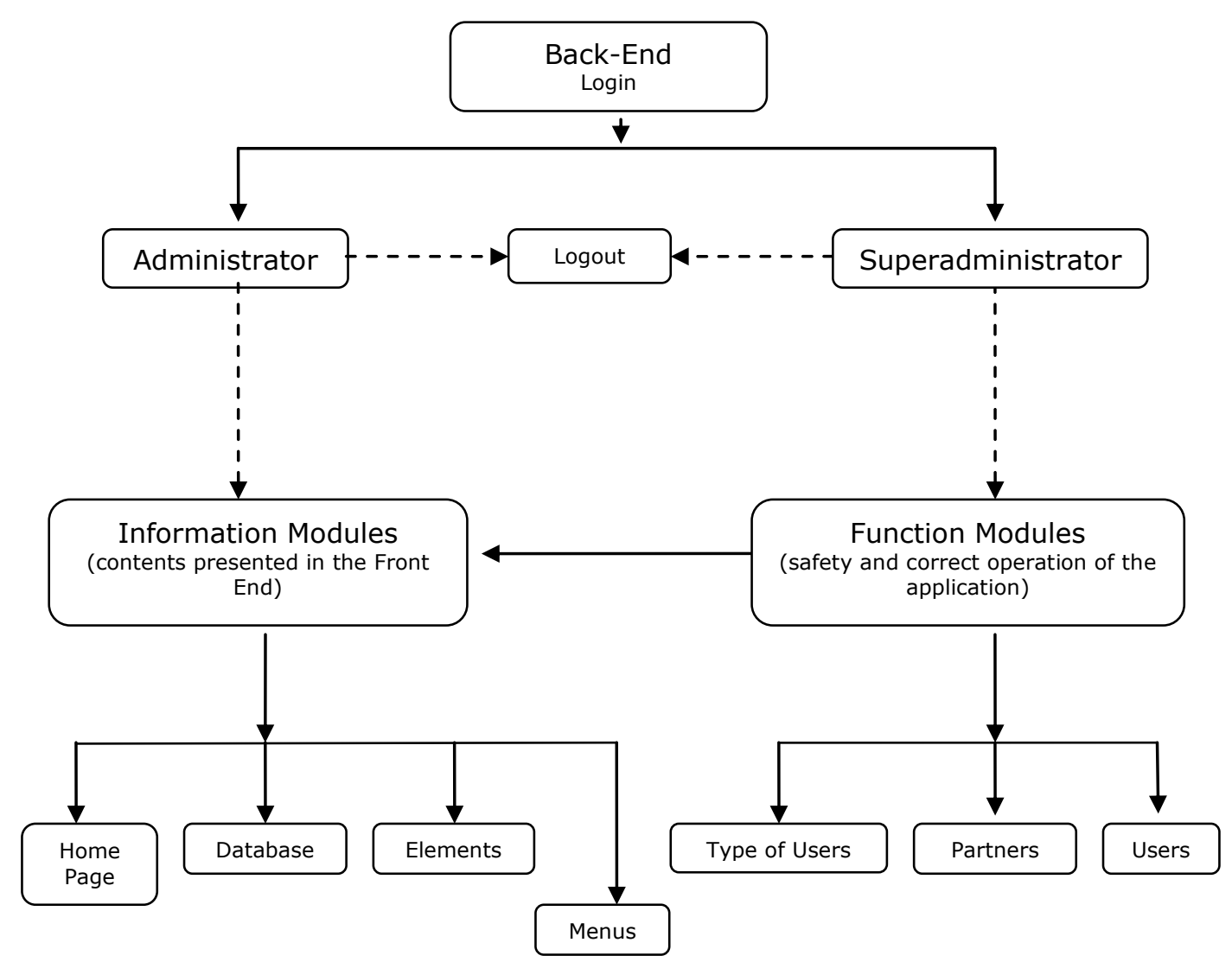

Figure 8. Flux diagram of the Backoffice. 


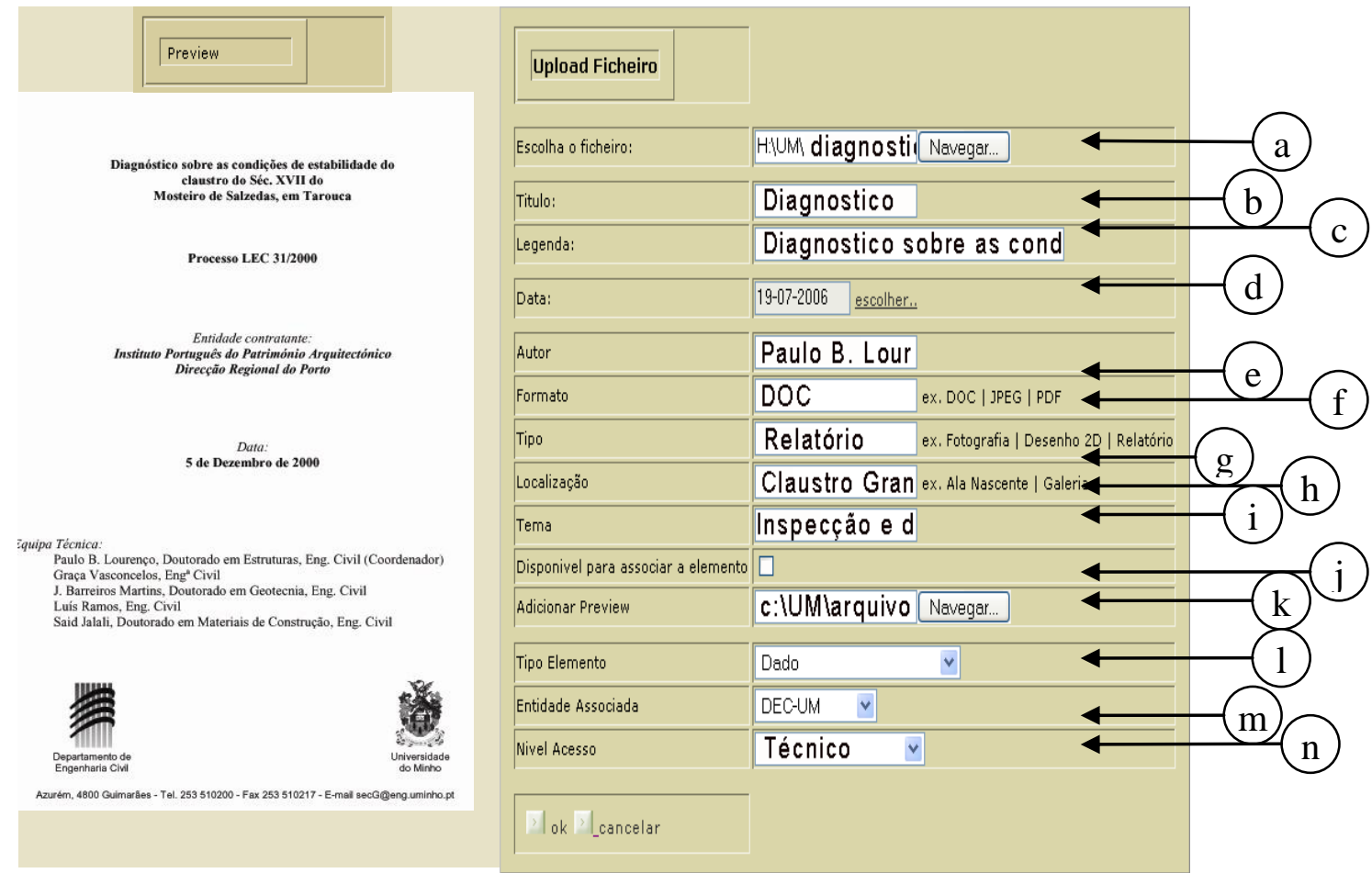

Figure 9. Database form: a) File name; b) Title; c) Legend; d) Date; e) Author; f) Format; g) Type; h) Localization; i) Subject; j) Association to element; k) Preview; 1) Type of Element; m) Partner; n) Level of access. 

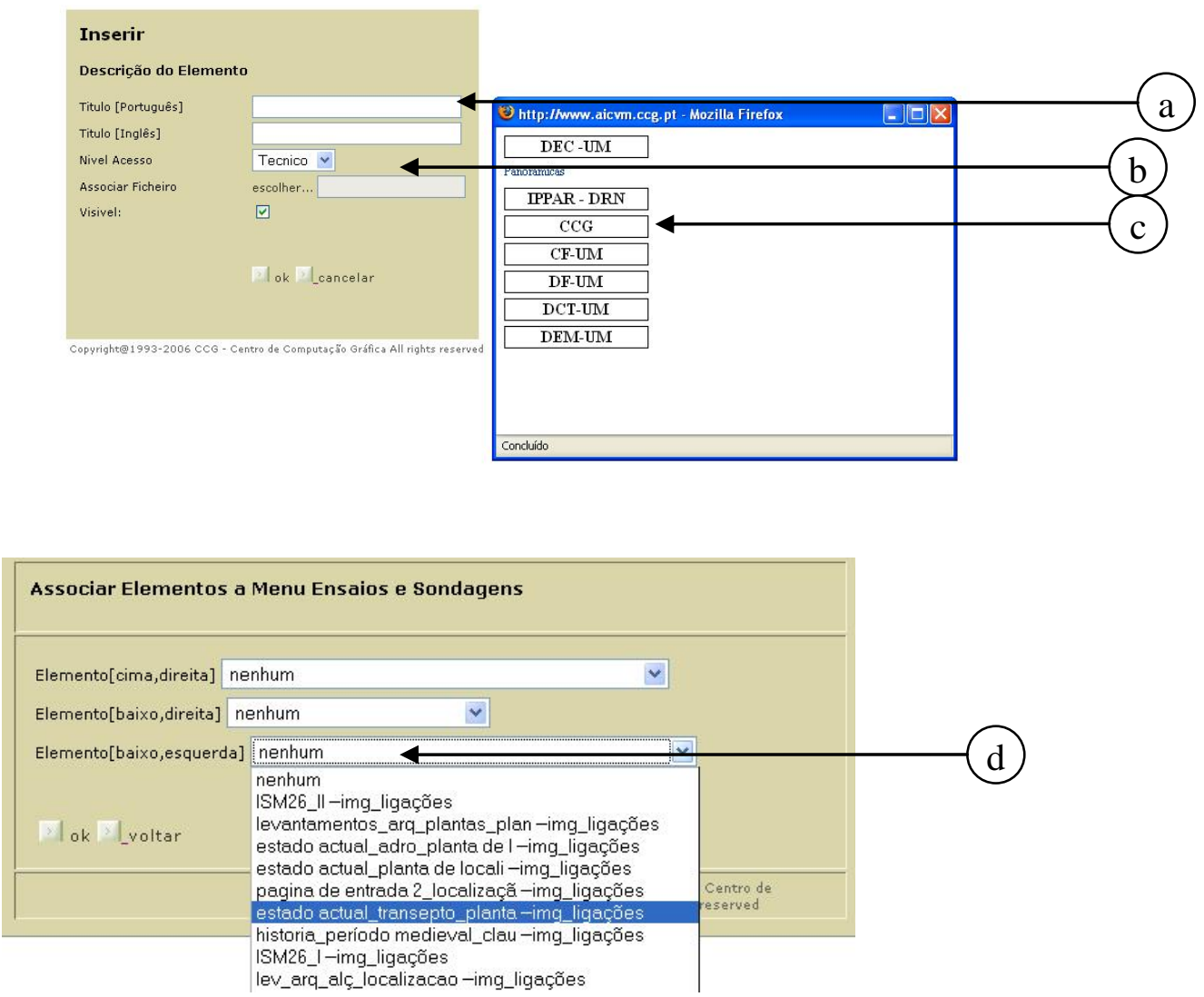

Figure 10. Example of creation of contents: a) Name of the element; b) Level of access; c) file in the database associated to the element; d) element associated to a menu. 

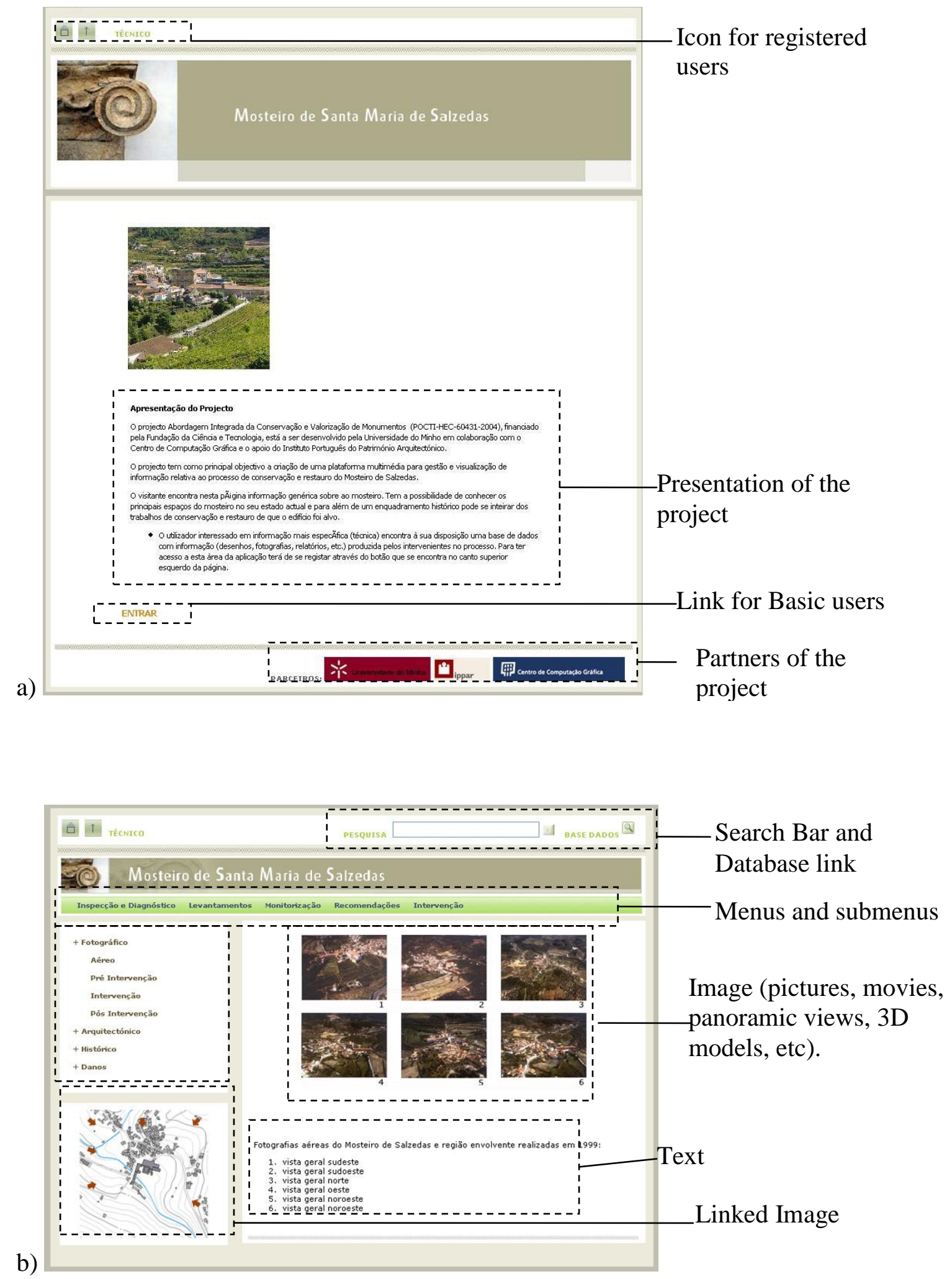

Figure 11. Views of the front end: a) home page; b) application for registered users. 

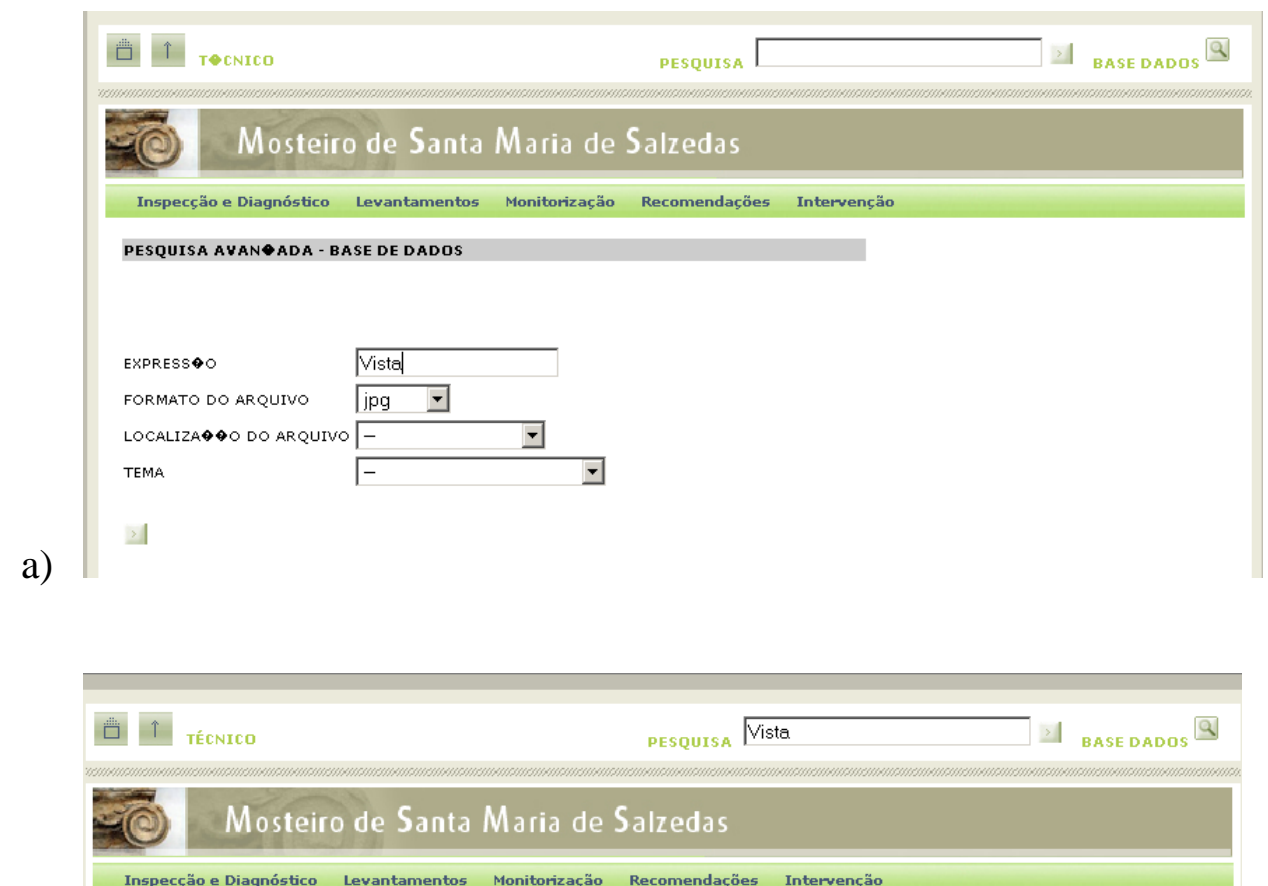

Inspecção e Diagnóstico Levantamentos Monitorização Recomendaçöes Intervenção

\begin{tabular}{|c|c|c|c|c|c|c|c|}
\hline TITULO & LEGENDA & TIPO & FORMATO & LOCALIZAÇão & TEMA & & \\
\hline pagent2_vista aerea & conteudo da pagina d & Fotografia & jpg & Global & Estado Actual & $n / p$ & download \\
\hline lev_fot_aer_vista ae & vista aerea do moste & Fotografia & jpg & Global & Levantamentos & $n / p$ & download \\
\hline lev_fot_aer_vista ae & Vista aerea do moste & Fotografia & jpg & Global & Levantamentos & $n / p$ & download \\
\hline lev_fot_aer_vista ae & Vista aerea do moste & Fotografia & jpg & Global & Levantamentos & $n / p$ & download \\
\hline lev_fot_aer_vista ae & Vista aerea do moste & Fotografia & jpg & Global & Levantamentos & $n / p$ & download \\
\hline lev_fot_aer_vista ae & Vista aerea do moste & Fotografia & $\mathrm{jpg}$ & Global & Levantamentos & $n / p$ & download \\
\hline lev_fot_aer_vista ae & Vista aerea do moste & Fotografia & jpg & Global & Levantamentos & $n / p$ & download \\
\hline lev_fot_int_vista pa & Vista parcial do cla & Fotografia & $\mathrm{jpg}$ & $\begin{array}{l}\text { Claustro } \\
\text { Grande }\end{array}$ & Levantamentos & $n / p$ & download \\
\hline lev_fot_aer_vista Ae & Vista aerea sul do $\mathrm{M}$ & Fotografia & jpg & Global & Levantamentos & preview & download \\
\hline lev_fot_aer_Vista ae & Vista aerea oeste do & Fotografia & jpg & Global & Levantamentos & preview & download \\
\hline Lev_fot_PreInt_vista & Vista Parcial do Eir & Fotografia & jpg & $\begin{array}{l}\text { Claustro } \\
\text { Grande }\end{array}$ & Levantamentos & preview & download \\
\hline Lev_Fot_PreInt_Vista & Vista Parcial da Fac & Fotografia & jpg & $\begin{array}{l}\text { Claustro } \\
\text { Grande }\end{array}$ & Levantamentos & $n / p$ & download \\
\hline lev_fot_posint_vista & Vista oeste da nave & Fotografia & jpg & Igreja & Levantamentos & $n / p$ & download \\
\hline ClaustroQ_Vista2 & $n / 1$ & Fotografia & jpg & $\begin{array}{l}\text { Claustro } \\
\text { Pequeno }\end{array}$ & $\begin{array}{l}\text { Inspecçãa e } \\
\text { Diagnóstico }\end{array}$ & $n / p$ & download \\
\hline
\end{tabular}

b)

Figure 12. Typical view of the database: a) search form; b) results displayed. 